\title{
Properties of the COPD assessment test in a cross-sectional European study
}

\author{
P.W. Jones*, G. Brusselle ${ }^{\#}$, R.W. Dal Negro`, M. Ferrer ${ }^{+}$, P. Kardos ${ }^{\S}$, M.L. Levy ${ }^{\ddagger}$, \\ T. Perez ${ }^{* *}$, J.J. Soler Cataluña ${ }^{\# \#}$, T. van der Molen ${ }^{\uparrow ฯ}$, L. Adamek ${ }^{++}$and N. Banik ${ }^{\S \S}$
}

ABSTRACT: A short, easy-to-use health status questionnaire is needed in the multidimensional assessment of chronic obstructive pulmonary disease (COPD) in routine practice.

The performance of the eight-item COPD assessment test (CAT) was analysed in 1,817 patients from primary care in seven European countries. The CAT has a scoring range of $0-40$ (high score representing poor health status).

Mean CAT scores indicated significant health status impairment that was related to severity of airway obstruction, but within each Global Initiative for Obstructive Lung Disease stage (I to IV) there was a wide range of scores (I: $16.2 \pm 8.8$; II: $16.3 \pm 7.9$; III: 19.3 \pm 8.2 ; and IV: $22.3 \pm 8.7$; I versus II, $p=0.88$; II versus III, $p<0.0001$; III versus IV, $p=0.0001$ ). CAT scores showed relatively little variability across countries (within $\pm 12 \%$ of the mean across all countries). Scores were significantly better in patients who were stable $(17.2 \pm 8.3)$ versus those suffering an exacerbation $(21.3 \pm 8.4)(p<0.0001)$; and in patients with no $(17.3 \pm 8.1)$ or one or two $(16.6 \pm 8.2)$ versus three or more $(19.7 \pm 8.5)$ comorbidities $(p<0.0001$ for both). The CAT distinguished between classes of other impairment measures and was strongly correlated with the St George's Respiratory Questionnaire $(r=0.8, p<0.0001)$.

The CAT is a simple and easy-to-use questionnaire that distinguishes between patients of different degrees of COPD severity and appears to behave the same way across countries.

KEYWORDS: Chronic obstructive pulmonary disease, COPD assessment test, health-related quality of life, primary care

hronic obstructive pulmonary disease (COPD) is an inflammatory disease of the lungs characterised by progressive and partially reversible airflow obstruction associated with an abnormal inflammatory response of the lungs to noxious particles or gases, primarily caused by cigarette smoking [1, 2]. The prevalence of COPD and associated mortality is predicted to increase in the coming decades [3] and with it a considerable economic and social burden. While COPD has traditionally been associated with older ( $>50$ yrs) males, recent evidence suggests that the disease is already present in $20-45 \mathrm{yr}$ olds and that sex differences are becoming less pronounced [4].

Effective management of COPD involves an overall approach that aims to relieve symptoms, improve exercise tolerance, health status and survival, and to prevent complications and exacerbations [1, 2]. It is now recognised that the assessment of dyspnoea, exercise performance and health status provides important additional information to pulmonary function measures [5]. Current COPD-specific health status measurements, including the St George's Respiratory Questionnaire (SGRQ) [6, 7] and Chronic Respiratory Disease Questionnaire [8], have been validated and used extensively in clinical trials. Such questionnaires are complex and time-consuming to complete. There is a requirement in clinical practice for a simple, short questionnaire that would allow routine assessment of patients' health status in all healthcare settings, particularly in primary care where the majority of COPD patients are managed.

The COPD assessment test (CAT) is a short, easyto-complete health status tool that has been developed to help patients and their clinicians assess and quantify the symptoms and impacts of COPD and enable better communication between patients and physicians about these consequences of their disease. During the development

\section{AFFILIATIONS}

*Division of Clinical Science, St George's, University of London, London,

${ }^{f}$ Division of Community Health Sciences, University of Edinburgh, Edinburgh, UK

${ }^{\#}$ Dept of Respiratory Medicine, Ghent University Hospital, Ghent, Belgium.

"Lung Dept, Orlandi General Hospital, Bussolengo, Italy. +Health Services Research Unit, IMIM - Hospital del Mar Research Institute, Barcelona,

\#\#Pneumology Unit, Requena General Hospital, Valencia, Spain. ${ }^{\text {S}}$ Respiratory Medicine, Maingau Hospital, Frankfurt am Main,

${ }^{\S \S}$ Biostatistics and Epidemiology, GlaxoSmithKline, Munich, Germany. **Pulmonology Dept, Lille University Hospital, Lille,

"Respiratory Centre of Excellence, GlaxoSmithKline, Marly le Roi, France.

"University Medical Centre Groningen, Groningen, The Netherlands.

CORRESPONDENCE

P.W. Jones

Division of Clinical Science

St George's University of London Cranmer Terrace

London

SW17 ORE

UK

E-mail: pjones@sghms.ac.uk

Received:

Nov 162010

Accepted after revision:

March 282011

First published online:

May 122011 
of the CAT, an initial qualitative survey involved interviews with both patients and physicians, and identified 21 items covering all aspects of COPD that affect a patient's health [9]. Subsequent item reduction and validation studies (partly using data from this survey) resulted in the final eight-item CAT questionnaire with good sensitivity and reliability [10].

This paper describes the properties of the CAT, tested in a European, cross-sectional health status study in a large population of COPD patients from primary care.

\section{METHODS}

Full details of the study design for this survey have been reported previously [11] and are summarised here.

This health-related quality of life (HRQoL) survey in COPD in Europe was a cross-sectional, epidemiological, non-randomised study, conducted by primary care practitioners (PCPs) from Belgium, France, Germany, Italy, the Netherlands, Spain and the UK. Patients with an established history of COPD (aged $\geqslant 30$ yrs at diagnosis of COPD with a smoking history $\geqslant 10$ pack-yrs) were eligible. Patients with COPD, presenting at their PCP practices for any reason and who fulfilled the entry criteria, were invited to participate. Patients completed four HRQoL questionnaires at a single study visit, including the St George's Respiratory Questionnaire - COPD specific (SGRQ-C) [6], the generic Short Form health survey (SF-12) [12], the Functional Assessment of Chronic Illness Therapy (FACIT) Fatigue scale [13] and the 21 CAT candidate items. The investigator scored the patient's reported breathlessness using the Medical Research Council (MRC) Dyspnoea Scale [14]. Severity of COPD was assessed clinically by the PCP as mild, moderate, severe or very severe. Global Initiative for Chronic Obstructive Lung Disease (GOLD) stage severity was calculated retrospectively using lung function data obtained at or within 6 months of the assessment. An exacerbation was defined as a worsening of symptoms that required oral corticosteroids and/ or antibiotics and/or hospitalisation. The type and number of comorbidities were recorded. Patients with cardiovascular comorbidities were defined as those with at least one of: myocardial infarction, stroke, heart failure, treated hypertension, treated angina pectoris or treated arrhythmia. All studyrelated assessments, including completion of the HRQoL questionnaires, were completed at the single study visit in the primary care practice. The questionnaires were completed after all other assessments had been conducted.

Only the results related to CAT will be further discussed in this paper as other results have been previously reported [11].

\section{CAT questionnaire}

In this study, the 21 candidate CAT items were administered to all patients. Data from a sample of these patients, together with data from patients in the USA were used to identify the eight items that form the CAT [10]. The analysis presented here is confined to the eight items that now form the CAT. These eight items cover: cough, phlegm, chest tightness, breathlessness going up hills/stairs, activity limitations at home, confidence leaving home, sleep and energy.

Each item is scored from 0 to 5 giving a total score range from 0 to 40 , corresponding to the best and worst health status in patients with COPD, respectively. The CAT is designed to assess current health and does not specify a recall period. All translations of the CAT items from English were carried out with careful translation and back translation, followed by full linguistic and cultural validation and finally international harmonisation to ensure that the concepts contained in the items were the same regardless of language.

\section{Statistical analysis}

Sample size calculations for this study have been presented elsewhere [11].

Descriptive statistics, analysed using Statistical Analysis Systems version 9.1.3 software (SAS Inc, Cary, NC, USA), were used to report baseline characteristics and distribution of HRQoL questionnaire scores for the whole study population and subgroups split by country, demographic factors, COPD clinical status, GOLD stage and reported comorbidities.

Comparisons between classes of other impairment measures were tested using unpaired t-test. A two factor ANOVA was performed to check differences in CAT scores across countries.

Correlations between CAT score and other impairment measures were calculated using Spearman's rank correlation coefficient. Scatter plots and regression equations were also presented to further interpret these relationships. Tests for an effect of country on the relationship between CAT score and other HRQoL measures were performed using a general linear model. These multivariate models were re-run excluding the data from Italy and the UK to check for the potential influence of these two smallest-recruiting countries on the power of the related statistical tests in these models.

For all statistical tests, the applied comparison-wise significance level was 0.05 .

\section{RESULTS \\ Patient characteristics}

Patient flow through the survey is shown in figure 1 . Results for this manuscript are based on the 1,817 patients who had an age at diagnosis of COPD $\geqslant 30$ yrs, smoking history $>10$ packyrs, had completed at least one health outcomes questionnaire and who fulfilled the GOLD criterion by demonstrating forced expiratory volume in $1 \mathrm{~s}$ (FEV1) to forced vital capacity ratio $<70 \%$.

The clinical characteristics of this population have been described previously [11], and are summarised in table 1 . In brief, the majority of patients were male with a mean age of 65 yrs, mean smoking history of 40 pack-yrs and mean FEV1 of $1.6 \mathrm{~L}$ ( $56.7 \%$ of predicted). The proportion of patients reporting an exacerbation at the study visit, increased with increasing COPD severity, based on GOLD staging. There was no difference in the numbers of exacerbations reported in the 6 months before the study between GOLD stages I and II; however, there was a stepwise increase between stages III and IV.

\section{CAT scores}

CAT scores showed significant impairment in health status across all COPD severities, even in patients with mild disease, regardless of whether severity was assessed by PCP or classified by GOLD stage (fig. 2). There was wide variation 


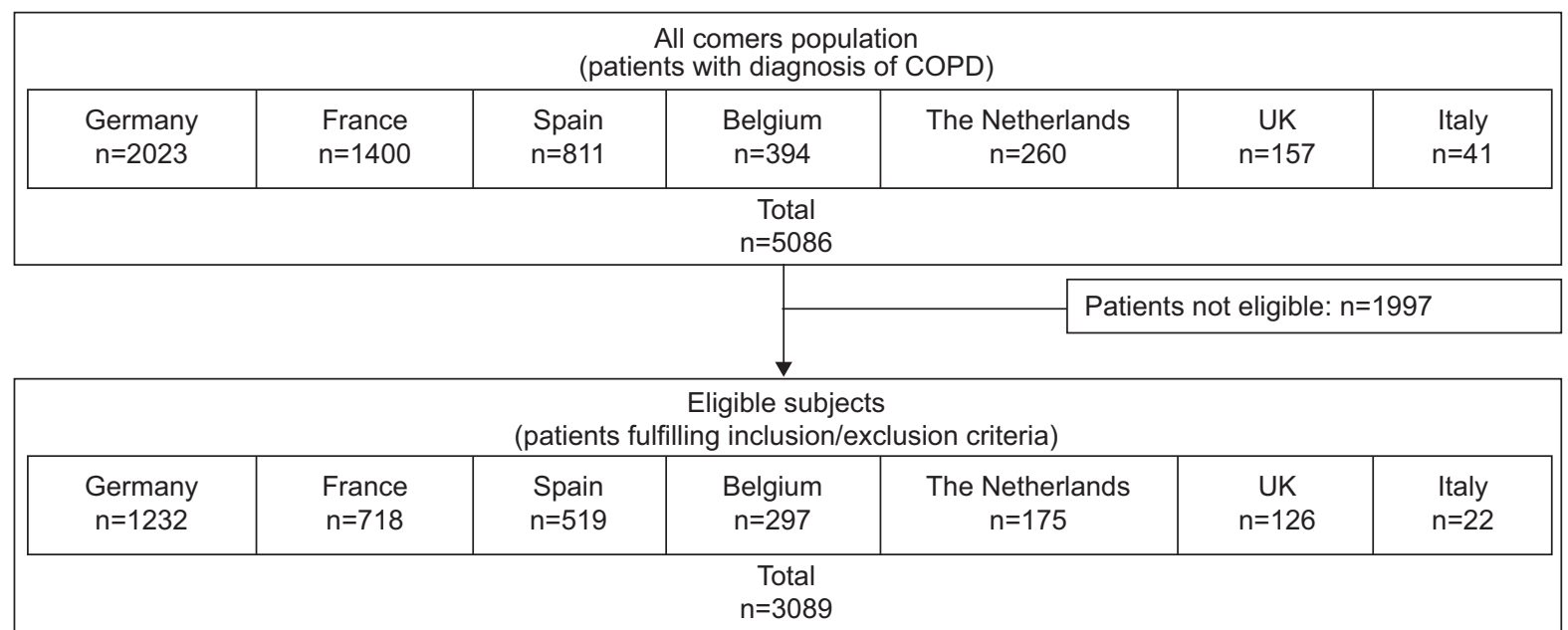

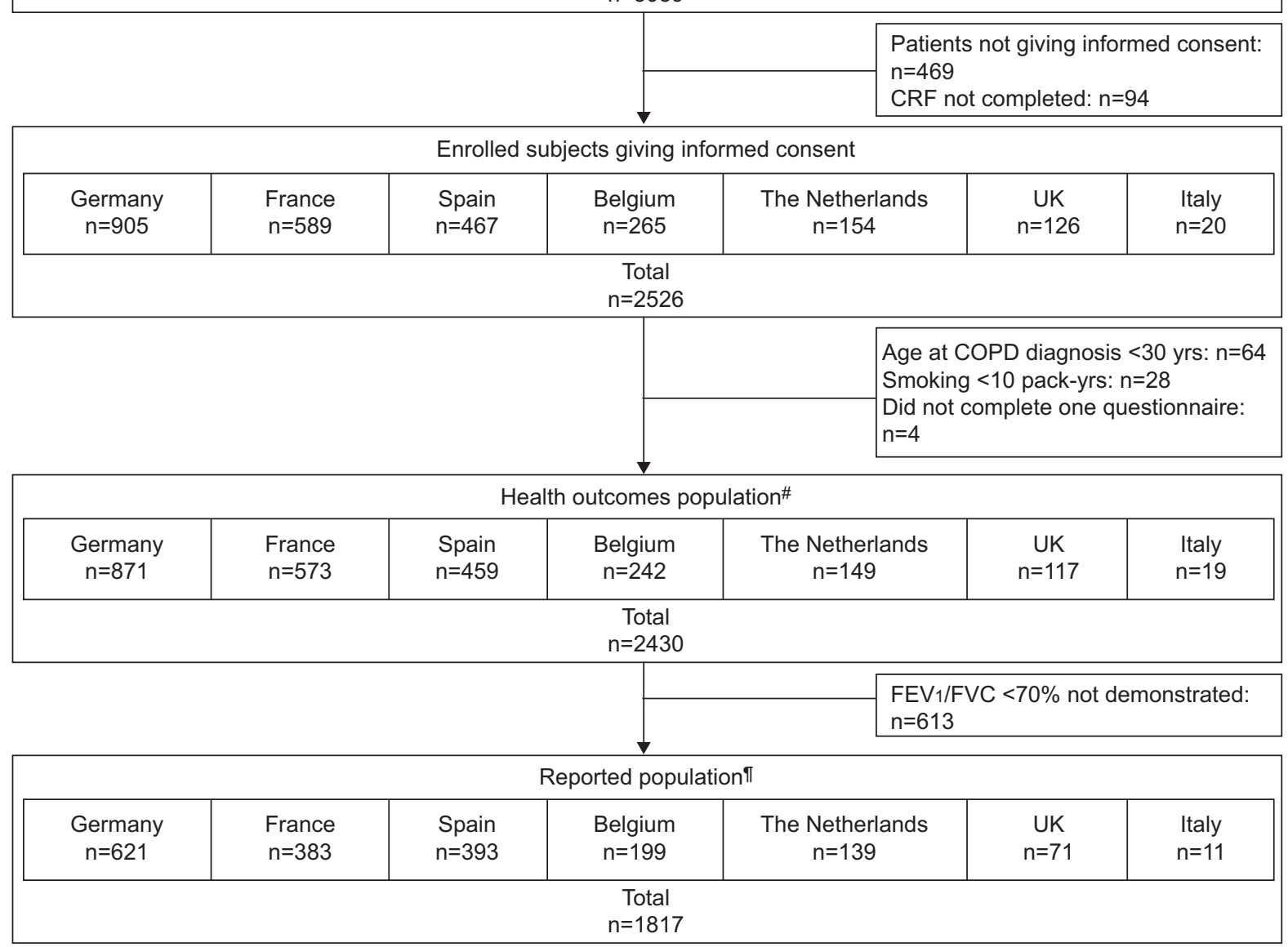

FIGURE 1. Patient flow through the European health-related quality of life survey. ${ }^{*}$ : health outcomes population consisted of patients with: 1) age at diagnosis of chronic obstructive pulmonary disease (COPD) $\geqslant 30 \mathrm{yrs}$; 2) smoking history $>10$ pack-yrs; and 3) at least one health outcomes questionnaire completed; ": reported population consisted of the health outcomes population and demonstrating a forced expiratory volume in $1 \mathrm{~s}$ (FEV1) to forced vital capacity (FVC) ratio < $70 \%$. CRF: case report form. Reproduced from [11] with permission from Elsevier.

in health status impairment within each severity group, demonstrated by large standard deviations around the mean score.

There were no differences in CAT scores between males (17.6, 95\% CI 17.2-18.1) and females (18.0, 95\% CI 17.3-18.8), or between younger ( $\leqslant 65$ yrs) $(18.0,95 \%$ CI $17.4-18.5)$ versus older (17.5, 95\% CI 17.0-18.1) patients (online supplementary table).

\section{Effect of exacerbations and comorbidities on CAT scores}

At the time of the study, 237 patients were experiencing an exacerbation; in these patients, CAT scores were significantly higher (i.e. worse health status) than in patients who were stable (fig. 3). The presence of three or more reported comorbidities was associated with significantly worse health status (higher CAT scores) compared with none, or one or two comorbidities (fig. 3). There was no difference in CAT scores 
TABLE 1 Demographic and clinical characteristics of chronic obstructive pulmonary disease (COPD) patients

\begin{tabular}{|c|c|c|c|c|c|}
\hline \multirow[t]{2}{*}{ Characteristic } & \multicolumn{4}{|c|}{ GOLD staging $^{\#}$} & \multirow[t]{2}{*}{ Reported populatior } \\
\hline & I & II & III & IV & \\
\hline Subjects $n$ & 223 & 868 & 551 & 144 & 1817 \\
\hline Age yrs & $65.3 \pm 9.7$ & $65.0 \pm 9.8$ & $65.0 \pm 9.5$ & $63.3 \pm 9.5$ & $64.9 \pm 9.6$ \\
\hline Males & $144(64.6)$ & $610(70.3)$ & $413(75.0)$ & $122(84.7)$ & $1305(71.8)$ \\
\hline \multicolumn{6}{|c|}{ Exacerbations on study day } \\
\hline Stable disease & $204(91.5)$ & 777 (89.5) & $461(83.7)$ & $110(76.4)$ & $1580(87.0)$ \\
\hline Exacerbation & $19(8.5)$ & $91(10.5)$ & 90 (16.3) & 34 (23.6) & $237(13.0)$ \\
\hline \multicolumn{6}{|c|}{ Exacerbations in past 6 months requiring } \\
\hline Antibiotics & $117(52.5)$ & $458(52.8)$ & $318(57.7)$ & $93(64.6)$ & $1005(55.3)$ \\
\hline Oral corticosteroids & $66(29.6)$ & $276(31.8)$ & $205(37.2)$ & $70(48.6)$ & $632(34.8)$ \\
\hline \multicolumn{6}{|l|}{ SF-12 ${ }^{+}$} \\
\hline PCS & $39.8 \pm 8.8$ & $39.3 \pm 8.7$ & $35.7 \pm 8.7$ & $31.7 \pm 8.6$ & $37.7 \pm 9.1$ \\
\hline MCS & $47.4 \pm 11.8$ & $47.9 \pm 11.3$ & $47.0 \pm 12.0$ & $43.7 \pm 12.9$ & $47.2 \pm 11.8$ \\
\hline $\mathrm{FACIT}^{\S}$ & $36.4 \pm 11.0$ & $36.3 \pm 10.8$ & $32.5 \pm 12.1$ & $28.7 \pm 12.1$ & $34.5 \pm 11.6$ \\
\hline \multicolumn{6}{|l|}{ MRC dyspnoea scale ${ }^{f}$} \\
\hline 1 & $65(29.1)$ & $207(23.8)$ & $55(10.0)$ & $15(10.4)$ & $344(18.9)$ \\
\hline 2 & $88(39.5)$ & $392(45.2)$ & $180(32.7)$ & $23(16.0)$ & $694(38.2)$ \\
\hline 3 & $42(18.8)$ & $181(20.9)$ & $166(30.1)$ & $29(20.1)$ & $427(23.5)$ \\
\hline 4 & 25 (11.2) & $70(8.1)$ & $125(22.7)$ & $43(29.9)$ & $271(14.9)$ \\
\hline 5 & $3(1.3)$ & $17(2.0)$ & $24(4.4)$ & $34(23.6)$ & $79(4.3)$ \\
\hline
\end{tabular}

Data presented as mean \pm SD or $n(\%)$, unless otherwise stated. GOLD: Global Initiative for Chronic Obstructive Lung Disease; FEV1: forced expiratory volume in 1 s; \% pred: \% predicted; SGRQ: St George's Respiratory Questionnaire; SF-12: Short Form health survey; PCS: physical component score; MCS: mental component score; FACIT: Functional Assessment of Chronic IIIness Therapy Fatigue scale; MRC: Medical Research Council. \#: FEV1 (\% pred) is missing for 31 patients, therefore they are not classifiable into GOLD stages; ${ }^{\bullet}$ : a lower score represents a better quality of life; ${ }^{+}:$a higher score represents a better quality of life; ${ }^{\text {s: }}$ a higher score indicates less

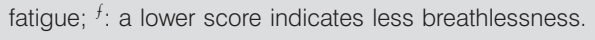

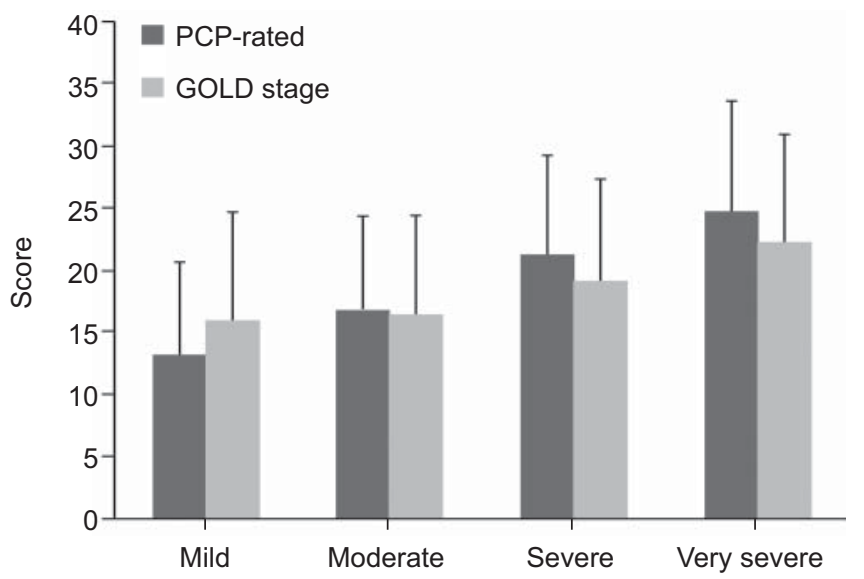

FIGURE 2. COPD assessment test score by primary care practitioner (PCP)rated chronic obstructive pulmonary disease (COPD) severity and Global Initiative for Chronic Obstructive Lung Disease (GOLD) staging. between patients with or without cardiovascular comorbidities (fig. 3).

\section{CAT scores by country}

CAT scores in all countries showed an approximately normal distribution, as evidenced by the similarity between mean and median values in table 2 . There was relatively little difference between countries, since the difference between the country with the highest mean score and that with the lowest was only $23 \%$ of the mean across all the countries (table 2). It should be noted that the analyses in this study were re-run after excluding patients from Italy and the UK since these formed $<5 \%$ of the total, but the results were no different, so we have reported the intention-to-study population.

\section{Association between CAT scores and other COPD impairment measures}

The difference in CAT score between GOLD stages I and II was small and not statistically significant (table 3). By contrast, the difference between PCP-judged clinical severity grades mild and moderate was significant (table 3). CAT score differences 

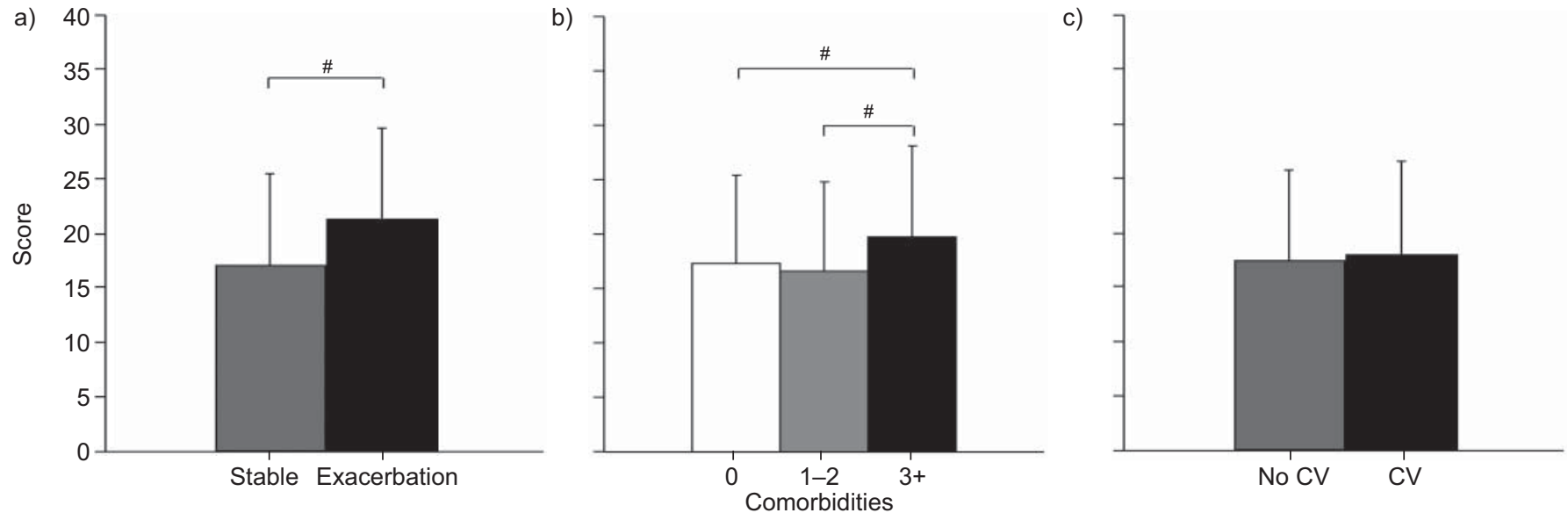

FIGURE 3. a) COPD assessment test (CAT) score by chronic obstructive pulmonary disease (COPD) status on study day (mean+SD) (stable disease ( $\mathrm{n}=1,580)$ versus exacerbation $(n=237))$. b) CAT score by number of comorbidities (mean+SD) (none $(n=350)$, one or two $(n=870)$, or three or more $(n=597)$ ). c) CAT score by cardiovascular comorbidities (mean+SD) (CV) (present $(n=1,061)$ or absent $(n=756)$ ). Cardiovascular comorbidities are defined as the patient having myocardial infarction, stroke or heart failure or patient being treated for hypertension, angina pectoris or arrhythmia. ${ }^{*}: p<0.0001$.

between GOLD stages II-III and III-IV were significant. For PCP-rated clinical severity, there was a consistent difference in CAT score between all stages of severity (fig. 2). The relationship between CAT score and GOLD stage was similar across countries, as shown by a nonsignificant $(p=0.40)$ effect of country as an interaction term in an ANOVA that tested the relationship between CAT and GOLD stage. This finding remained unchanged when the models were re-run without the data from Italy and the UK.

CAT scores clearly distinguished between SGRQ score categories (quartiles); the differences between all categories was statistically significant (all $\mathrm{p}<0.0001)$ (table 3 ). CAT scores also showed significant differences between MRC dyspnoea scale grades (table 3).

The CAT score was strongly correlated with SGRQ total score $(\mathrm{r}=0.84)$ (fig. 4) and showed moderate to strong correlations with generic HRQoL questionnaires: SF-12 physical component score, $\mathrm{r}=-0.65$; SF-12 mental component score, $\mathrm{r}=-0.58$; and FACIT, $r=-0.77$. In contrast, the CAT score had only a weak negative correlation with FEV1 \% predicted (fig. 4).

The strength of these correlations varied between countries; however, when tested in a general linear model, the slope of these relationships did not differ significantly between countries.

\section{DISCUSSION}

This paper summarises the performance of the disease-specific CAT questionnaire in a large population of COPD patients from primary care, across all severities of airway obstruction. Results showed significant impairment in health status that was related to COPD severity, whether based on GOLD spirometric staging, clinician-judged severity, MRC dyspnoea score, or disease-specific or generic health status scores. The study also confirmed an observation made in a much smaller number of patients in secondary care [10], that patients presenting to their PCP with an exacerbation have worse health scores than those who are stable. The proportion of patients presenting with an exacerbation, and the relative frequency of severe exacerbations within those patients, was higher in patients with higher CAT scores.

The CAT scores were the same in males and females and were not influenced by age. This suggests that symptoms and health status impairment are the main drivers for patients' attendance in primary care, rather than demographic factors. This would also explain the high CAT scores seen in patients with GOLD stage I. The presence of three or more comorbidities was associated with higher scores, compared with patients with two or fewer comorbidities, but the difference in score was relatively small (approx 2.5 units or $<15 \%$ of the score of

\section{TABLE 2 COPD assessment test (CAT) scores by country}

$\begin{array}{lllll}\text { Belgium France } \quad \text { Germany } \quad \text { Italy Netherlands } & \text { Spain } & \begin{array}{c}\text { Reported } \\ \text { population }\end{array}\end{array}$

\begin{tabular}{|c|c|c|c|c|c|c|c|c|}
\hline Subjects $n$ & 199 & 383 & 621 & 11 & 139 & 393 & 71 & 1817 \\
\hline Mean $\pm S D$ & $18.8 \pm 9.2$ & $18.5 \pm 8.5$ & $18.8 \pm 7.7$ & $18.9 \pm 8.2$ & $14.6 \pm 7.7$ & $15.9 \pm 8.7$ & $17.8 \pm 8.2$ & $17.7 \pm 8.4$ \\
\hline Median & 18.0 & 18.0 & 18.0 & 18.0 & 15.0 & 15.0 & 16.0 & 17.0 \\
\hline 75th percentile & 25.0 & 24.0 & 24.0 & 25.0 & 20.0 & 21.0 & 24.0 & 24.0 \\
\hline
\end{tabular}




\begin{tabular}{|c|c|c|c|}
\hline \multirow[t]{2}{*}{ TABLE 3} & \multicolumn{3}{|c|}{$\begin{array}{l}\text { Differences in COPD assessment test (CAT) } \\
\text { scores between classes of other COPD } \\
\text { impairment measures }\end{array}$} \\
\hline & CAT score & $\begin{array}{c}\text { Difference } \\
\text { between classes }\end{array}$ & p-value \\
\hline \multicolumn{4}{|l|}{ GOLD stage } \\
\hline I & $16.2 \pm 8.8$ & -0.1 & NS \\
\hline$\|$ & $16.3 \pm 7.9$ & $\begin{array}{l}-0.1 \\
-3.0\end{array}$ & $<0.0001$ \\
\hline III & $19.3 \pm 8.2$ & -3.0 & 0.0001 \\
\hline \multicolumn{4}{|c|}{ PCP-rated COPD severity } \\
\hline Mild & $13.2 \pm 7.5$ & & \\
\hline Moderate & $16.6 \pm 7.6$ & $\begin{array}{l}-3.4 \\
-4.7\end{array}$ & $<0.0001$ \\
\hline Severe & $21.3 \pm 8.1$ & $\begin{array}{l}-4.1 \\
-3.5\end{array}$ & $<0.0001$ \\
\hline Very severe & $24.8 \pm 8.9$ & & -0.000 \\
\hline \multicolumn{4}{|c|}{ Mean total SGRQ score ${ }^{\#}$} \\
\hline$\geqslant 0$ and $<30$ & $9.4 \pm 5.0$ & -5.6 & $<0.0001$ \\
\hline$\geqslant 30$ and $<4$ & $15.0 \pm 4.7$ & -4.9 & $<0.0001$ \\
\hline$\geqslant 45$ and $<6$ & $19.9 \pm 5.3$ & -7.8 & $<0.0001$ \\
\hline$\geqslant 60$ & $27.7 \pm 5.7$ & & \\
\hline \multicolumn{4}{|c|}{ MRC dyspnoea grade } \\
\hline 1 & $11.7 \pm 6.8$ & -4.0 & $<0.0001$ \\
\hline 2 & $15.7 \pm 7.0$ & -4.8 & $<0.0001$ \\
\hline 3 & $20.5 \pm 7.5$ & -2.9 & $<0.0001$ \\
\hline 4 & $23.5 \pm 7.4$ & -3.9 & $<0.0001$ \\
\hline 5 & $27.3 \pm 8.3$ & & \\
\hline
\end{tabular}

Data are presented as mean or mean $\pm \mathrm{SD}$, unless otherwise stated. COPD: chronic obstructive pulmonary disease; GOLD: Global Initiative for Chronic Obstructive Lung Disease; PCP: primary care practitioner; SGRQ: St George's Respiratory Questionnaire; MRC: Medical Research Council; NS: nonsignificant. \#: by SGRQ quartiles.

patients with two or fewer comorbidities). These findings suggest that the CAT is not affected by low levels of comorbidity. The relationship between high levels of comorbidity and higher CAT scores is consistent with the observation that comorbidity rates are similar in GOLD stages I and II but are higher in GOLD III and IV disease [15]. Cardiovascular comorbidity, as defined here, did not influence the CAT score, even though $50 \%$ of patients were diagnosed with either a cardiovascular comorbidity that was potentially symptomatic or multiple cardiovascular comorbidities simultaneously.

One of the most notable findings of the current survey was the small difference in health status impairment between patients in GOLD stages I and II seen with the CAT. Similarly, only small differences between these two GOLD stages were seen with the SGRQ-C, SF-12, proportion of patients with high MRC grades and frequency of exacerbations [11]. It is noteworthy, however, that the CAT scores were clearly different between patients rated by their physicians to be mild or moderate, suggesting that physicians take more than just the degree of airway obstruction into account when assessing COPD severity. These results suggest that the CAT provides a standardised assessment of the severity of the patient's disease that is complementary to spirometry, which may be especially important in patients who have mild-moderate airflow limitation. Spirometry is clearly
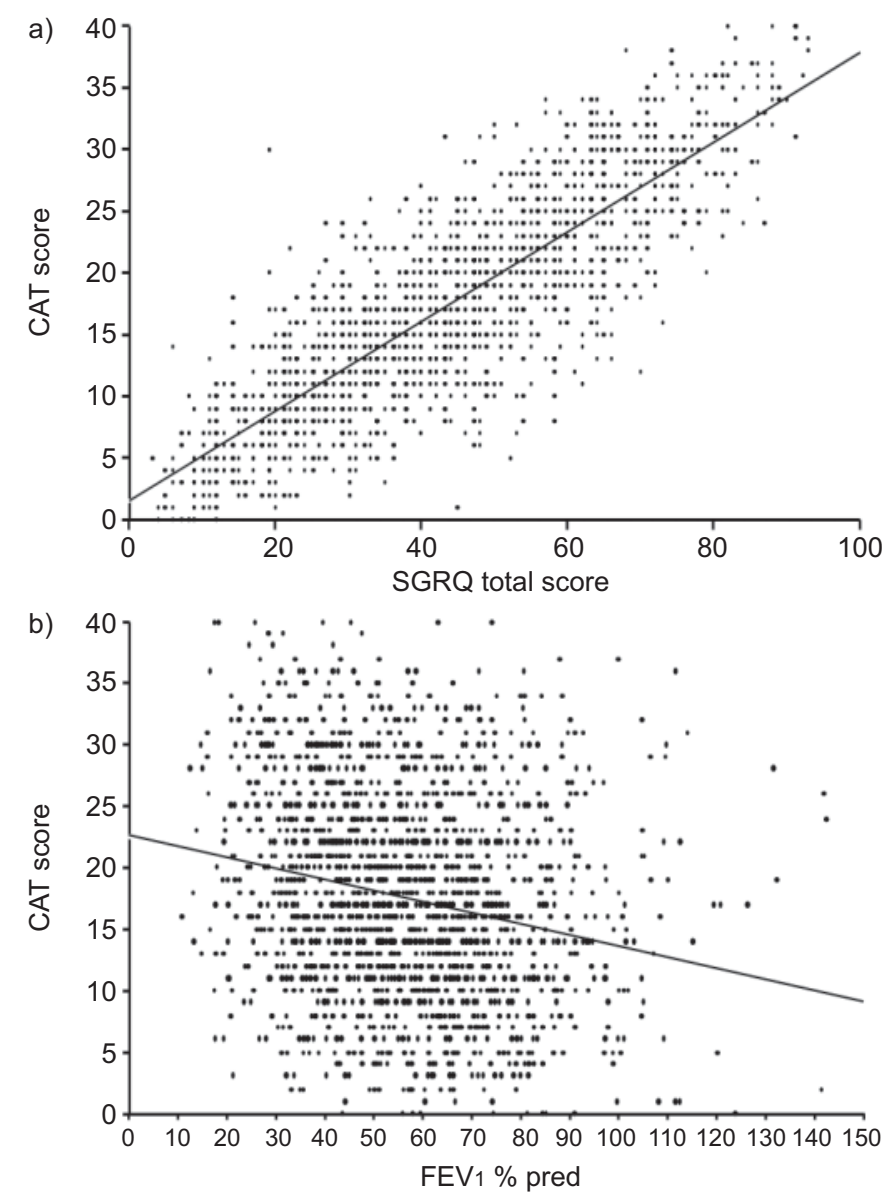

FIGURE 4. a) Scatter plot of correlation between St George's Respiratory Questionnaire (SGRQ) total score and COPD assessment test (CAT) score. Regression equation: CAT score $=1.54+0.36 \times \operatorname{SGRQ~}(r=0.84 ; p<0.001)$. b) Scatter plot of correlation between forced expiratory volume in $1 \mathrm{~s}$ (FEV1) \% predicted (\% pred) and CAT score. Regression equation: CAT score $=22.6-0.09 \times F E V_{1}$ $(r=-0.23 ; p<0.001)$. COPD: chronic obstructive pulmonary disease.

insufficient for a precise phenotyping of COPD patients, as recently demonstrated by studies using cluster analysis [16-18], highlighting the need for a multidimensional assessment of COPD. Short questionnaires such as the CAT are likely to offer relevant alternatives to complex tools such as the SGRQ, providing PCPs with a comprehensive and objective, but not time-consuming, assessment.

One of the limitations of the current survey is that the eight items that form the CAT were presented to the patients along with 13 other candidate items that were eventually excluded from the final questionnaire. It is possible that the responses may be slightly different when the eight items are presented alone, but this effect is likely to be small. The extremely strong correlation between CAT and SGRQ, reported in this and an earlier analysis [10], suggest that the patients' responses to these eight items were valid. Indeed, the high correlation between SGRQ and CAT is remarkable considering the fact that they were developed using entirely different methodologies and have very different structures, layouts and response formats. This suggests that the underlying construct that they were both designed to test, i.e. "health status impairment due 
to $\mathrm{COPD}^{\prime \prime}$, is a valid entity. Perhaps the most important contribution of the CAT is that it brings this type of assessment into the arena of routine practice.

A further limitation was that this was a cross-sectional study, so it provides no indication of the responsiveness of the CAT over time and there is, as yet, no study-derived information on a minimally important clinical difference for CAT. Another limitation of the study is that countries were chosen on the basis of representing large COPD populations, and were all from Western Europe, so not all European countries are reflected in the dataset. There were also some differences between countries in patient numbers. However the results of the between-country comparisons are encouraging and suggest that with careful translation into other languages, the measurement properties of the CAT described here should be reliable.

Unlike the physician's judgement of clinical severity, the CAT provides a standardised assessment and a numerical estimate of disease impact which appears to be reliable across languages and countries. It is, however, only one part of the clinician's toolkit, to be used alongside spirometry, exacerbation history and an assessment of comorbidity. Like any clinical assessment technique, its utility will only become fully apparent with time, but this study provides some evidence that the CAT will provide the practising physician with a reliable tool with which to measure the impact of COPD on their patients.

\section{SUPPORT STATEMENT}

Funding for this study was provided by GlaxoSmithKline (study number 111749)

\section{STATEMENT OF INTEREST}

Statements of interest for P.W. Jones, G. Brusselle, P. Kardos, M.L. Levy, J.J. Soler Cataluña, L. Adamek and N. Banik, and for the study itself, can be found at www.erj.ersjournals.com/site/misc/statements. xhtml

\section{ACKNOWLEDGEMENTS}

The authors would like to acknowledge editorial support in the form of development of the manuscript first draft, editorial suggestions to draft versions of the paper, assembling tables and figures, collating author comments, copyediting, fact checking and referencing which was provided by K. Hollingworth of Continuous Improvement Ltd, Kingsbridge, UK. This support was funded by GlaxoSmithKline.

\section{REFERENCES}

1 Celli BR, MacNee W, Agusti A, et al. Standards for the diagnosis and treatment of patients with COPD: a summary of the ATS/ERS position paper. Eur Respir J 2004; 23: 932-946.
2 The Global Initiative for Chronic Obstructive Lung disease (GOLD). Executive Summary: Global Strategy for the Diagnosis, Management, and Prevention of COPD. Medical Communications Resources, 2008. Available from www.goldcopd.com

3 Murray CJL, Lopez AD. Alternative projections of mortality and disability by cause 1990-2020: global burden of disease. Lancet 1997; 349: 1498-1504.

4 Viegi G, Pistelli F, Sherrill DL, et al. Definition, epidemiology and natural history of COPD. Eur Respir J 2007; 30: 993-1013.

5 Cazzola M, MacNee W, Martinez FJ, et al. Outcomes of COPD pharmacological trials: from lung function to biomarkers. Eur Respir J 2008; 31: 416-469.

6 Meguro M, Barley EA, Spencer S, et al. Development and validation of an improved, COPD-specific version of the St. George Respiratory Questionnaire. Chest 2007; 132: 456-463.

7 Jones PW. Interpreting thresholds for a clinically significant change in health status in asthma and COPD. Eur Respir J 2002; 19: 398-404.

8 Wijkstra PJ, TenVergert EM, Van Altena R, et al. Reliability and validity of the chronic respiratory questionnaire (CRQ). Thorax 1994; 49: 465-467.

9 Jones P, Harding G, Wiklund I, et al. Improving the process and outcome of care in COPD: development of a standardised assessment tool. Prim Care Respir J 2009; 18: 208-215.

10 Jones PW, Harding G, Berry P, et al. Development and first validation of the COPD Assessment Test. Eur Respir J 2009; 34: 648-654.

11 Jones PW, Brusselle G, Dal Negro RW, et al. Health-related quality of life in patients by COPD severity within primary care in Europe. Respir Med 2011; 1: 57-66.

12 Ware JE, Kosinski M, Keller SD. A 12-item short-form health survey: construction of scales and preliminary tests of reliability and validity. Med Care 1996; 34: 220-233.

13 Webster K, Odom L, Peterman A, et al. The Functional Assessment of Chronic Illness Therapy (FACIT) measurement system: validation of version 4 of the core questionnaire. Qual Life Res 1999; 8: 604.

14 Bestall JC, Paul EA, Garrod R, et al. Usefulness of the Medical Research Council (MRC) dyspnoea scale as a measure of disability in patients with chronic obstructive pulmonary disease. Thorax 1999; 54: 581-586.

15 Mannino DM, Thorn D, Swensen A, et al. Prevalence and outcomes of diabetes, hypertension and cardiovascular disease in COPD. Eur Respir J 2008; 32: 962-969.

16 Wardlaw A, Silverman M, Siva R, et al. Multi-dimensional phenotyping: towards a new taxonomy for airway disease. Clin Exp Allergy 2005; 35: 1254-1262.

17 Weatherall M, Travers J, Shirtcliffe PM, et al. Distinct clinical phenotypes of airways disease defined by cluster analysis. Eur Respir J 2009; 34: 812-818.

18 Burgel P-R, Paillasseur J-L, Caillaud D, et al. Clinical COPD phenotypes: a novel approach using principal component and cluster analyses. Eur Respir J 2010; 36: 531-539. 